\title{
Deletion analysis of spinal muscular atrophy in southern Indian population
}

\author{
Bhairavi Swaminathan, S. Shylashree ${ }^{1}$, Meera Purushottam, A. B. Taly ${ }^{1}$, Nalini A. ${ }^{1}$ \\ Molecular Genetics Laboratory, Departments of Psychiatry, and ${ }^{1}$ Neurology, National Institute of Mental Health and Neurosciences, \\ Bangalore, India
}

\begin{abstract}
Background: Proximal spinal muscular atrophy (SMA) is a genetically heterogeneous disease with paresis and muscle atrophy due to loss of anterior horn cell function. The survival of motor neuron gene (SMN) and neuronal apoptosis inhibitory protein (NAIP) play a primary role. Both the gene homologues exist as inverted duplications on Chromosome 5q. The telomeric/functional (SMN1) and the centromeric (SMN2) copies differ from each other in eight nucleotides. The $\mathrm{C} \rightarrow T$ transition (at Codon 280) within Exon 7 of SMN2 causes disruption of an exonic splicing enhancer (ESE) and/or creates an exonic splicing silencer (ESS) leading to abnormal splicing and a truncated protein. Objective: To determine the molecular genetics of SMN1 and NAIP genes in SMA from southern India. Materials and Methods: In the present study, 37 patients from the neuromuscular disorders clinic of National Institute of Mental Health and Neurosciences were assayed for the deletions in the SMN1 and NAIP genes using PCR-RFLP methods. Results: Among the SMA Type I patients, 43\% showed deletions of SMN1 and NAIP. In patients Type II SMA, 57\% showed deletions of the SMN1 exons. Conclusion: Thus, deletions were found to occur in $47.8 \%$ of the Type I and II patients. Lower sensitivity of gene deletion study in clinically suspected SMA needs further study as clinical diagnosis of SMA is not gold standard. However, the results do correlate with other studies conducted in India.
\end{abstract}

Key words: Genetics, southern India, spinal muscular atrophy

\section{Introduction}

Proximal spinal muscular atrophy (SMA) is a genetically heterogeneous disease with paresis and muscle atrophy due to loss of anterior horn cell function. ${ }^{[1]}$ The disease varies from onset in prenatal period to adulthood. ${ }^{[2]}$ This neuromuscular disorder is the second most common and lethal disorder with an incidence rate between 1 in 6000 to 1 in 10,000 live births, and a carrier frequency of 1 in 40 to 1 in $60 .{ }^{[3-6]}$

SMA is clinically divided into several subgroups, (Types I-IV) based on the age of onset and motor disabilities. ${ }^{[7]}$ SMA Type I (acute SMA; MIM 253300) also known as Werdnig-Hoffman disease has the most severe phenotype ${ }^{[8]}$ Onset of clinical symptoms in SMA Type I is by definition before the age of six months and progressive muscle weakness and subsequent leads to rapid progressive course in most and death before the age of two years. ${ }^{[9]}$ Children with Type II SMA (intermediate form; MIM 253550) show onset after six months. They can sit but are never able to stand or walk, unaided, and life expectancy is significantly reduced. In SMA Type III (Kugelberg-Welander disease; MIM 253400) there is a broader range of age at onset, patients with an age of onset before three years are classified as Type IIIa and those with onset after three years as Type IIIb. ${ }^{[10]}$ Such children are able to stand and walk unaided; however they become wheelchairbound in adolescence or adulthood. Patients with an age of onset beyond 30 years are classified as Type IV SMA. SMA can be confused with clinically overlapping neurological disorders ${ }^{[1]}$ and the subdivision between acute and chronic SMA is nearly arbitrary, with overlap between the groups. ${ }^{[1]}$

In 1990 the gene locus for Type I-III SMA was mapped by linkage studies to Chromosome 5q13. ${ }^{[1,11-13]}$ Chronic childhood onset SMA (SMAI, II and III) maps to a single locus of Chromosome 5q11.213.3. ${ }^{[13]}$ Among the candidate genes located in this region, the survival of motor neuron (SMN) gene and the neuronal apoptosis inhibitory (NAIP) gene were suggested to play an important role. ${ }^{[13-17]}$ The SM N and the NAIP genes are found as two homologous copies,

\footnotetext{
A. Nalini

Department of Neurology, National Institute of Mental Health and Neurosciences, Neuroscience Faculty Block, Hosur Road, Bangalore 560029 , India.
} E-mail: atchayaramnalini@yahoo.co.in 
existing as inverted duplications. Both the copies of SMN genes contain nine exons, and differ from each other in eight nucleotides and can be differentiated by the use of restriction enzymes. The sixth nucleotide of Exon 7 in SMN 2 contains a T nucleotide, which disrupts an exonic splicing enhancer and/or creates an exonic splicing silencer (ESS), leading to alternative splicing, resulting in skipping of Exon 7 in around 90\% of the SMN2 transcripts. These transcripts lead to the formation of an unstable and truncated protein that is degraded, thus making the SMN 1 the functional copy. In patients with SMA, SMN1 is found to be deleted in a homozygous fashion, with the SMN2 failing to compensate for the loss of SMN 1. ${ }^{[18,19]}$ Similar such reports have been published from different parts of India. ${ }^{[20,21]}$

\section{Materials and Methods}

\section{Clinical}

The institutional ethics committee approval was obtained for this study. Thirty-seven families with childhood $(n=30)$ and adult onset $(n=7)$ SMA were studied. Patients were investigated in the Department of Neurology at a tertiary care centre for neurological disorders and were recruited from the Neuromuscular Disorders clinic of the Institute. Clinical information and blood samples from 16 children of SMA I, and seven each from SMA II, SMA III and SMA IV were collected. The clinical details were recorded meticulously and those patients with SMA phenotype and who conformed to the clinical criteria proposed by the International SMA Consortium were included in the study. SMA Type I was considered in infants when there was severe weakness with inability to sit, generalized hypotonia, areflexia and feeble voice with onset at or before birth. When the clinical possibility was SMA Type I with onset before six months of life, electromyography was not performed and only few underwent muscle biopsy. SMA Type II was diagnosed when the onset was after six months of age and the child had severe symmetrical weakness (more proximal than distal) with hypotonia, severe motor disabilities, minipolymyoclonus / tremors, areflexia and absent ambulation. SMA Type III and IV were considered when onset was after three and 30 years of age respectively. These patients had symmetrical or asymmetrical predominantly proximal muscle weakness and wasting and particularly affecting the lower limbs with tremor of the hands and generalized markedly reduced or absent deep tendon reflexes. SMA II-IV patients underwent EMG studies and if consent was obtained, a muscle biopsy either from the biceps or quadriceps was done. The clinical findings were corroborated by EMG showing pattern of denervation with nerve conduction studies being normal. In addition, when available, muscle biopsy demonstrated neurogenic atrophy with groups of atrophic and hypertrophic fibers or fiber type grouping. None of the patients had evidence of contractures, facial weakness, myotonia or bulbar dysfunction to clinically suggest any other muscle disease and these were exclusion criteria.

\section{Genetics}

After written informed consent genomic DNA was isolated from peripheral blood by the salting out method. ${ }^{[22]}$ The DNA was then used for amplification of the target genes, by polymerase chain reaction (PCR) methods.

SMN Gene: The PCR amplification of SMN Exon 7 with

Forward Primer: 5'-

CTTCCTTTTATTTTCCTTACAGGGATT-3';

Reverse Primer: 5'-TCCACAAACCATAAAGTTTTAC-3' and Exon 8 with

Forward Primer: 5'-

GTAATAACCAAATGCAATGTGAA-3';

Reverse Primer: 5'-CTACAACACCCTTCTCACAG-3') were done as per the protocol of Wirth et al.. ${ }^{[23]}$ Both Exon 7 and 8 were amplified using the following PCR conditions: initial denaturation $95^{\circ} \mathrm{C}$ for $5 \mathrm{~min}$; followed by 34 cycles of $95^{\circ} \mathrm{C}$ for $30 \mathrm{sec} ; 55^{\circ} \mathrm{C}$ for $30 \mathrm{sec} ; 72^{\circ} \mathrm{C}$ for $30 \mathrm{sec}$; final extension of $72^{\circ} \mathrm{C}$ for $7 \mathrm{~min}$. The $135 \mathrm{bp}$ amplified product of Exon 7 was digested with Hinfl, and run on $12 \%$ PAGE. The presence of particular size bands allowed differentiation of SMN2 (SMN2 -100 bp, $35 \mathrm{bp}$ ) from SMN1 (SMN 1 -80 bp, $20 \mathrm{bp}, 35 \mathrm{bp}$ ) [Figure 1A]. The $185 \mathrm{bp}$ product of Exon 8 was digested with Ddel, and run on a $2 \%$ agarose gel. An undigested PCR product was indicative of the functional SMN1 [Figure 1B]. In a few patient samples a band of lighter

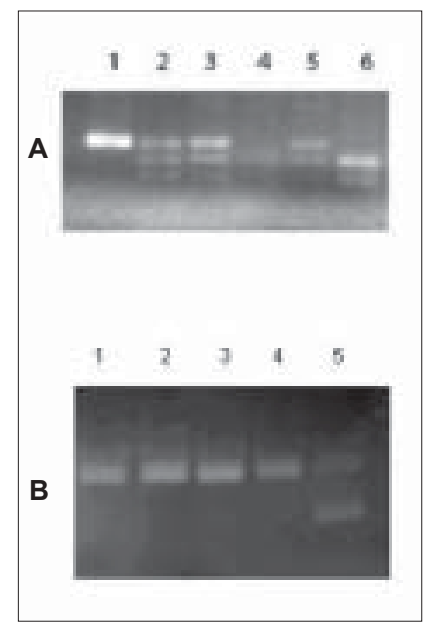

Figure 1: $(A, B)$ The Gel image after restriction digestion of the PCR products of Exon 7 and 8 respectively. (1A). Lane1: Sample lacking 100 bp band corresponding to SMN1. Lanes 2-5: Samples with SMN1 and SMN2. Lane M: Size standards of $185,115,85$ and $70 \mathrm{bp}$. (1B). Lane M: Size standards of sizes 185, 115, 85 and $70 \mathrm{bp}$. Lane 1,2,5,6: Restricted Samples with SMN1 and SMN2 present. Lane 3: Restricted Sample lacking 185 bp band corresponding to SMN1 
intensity was obtained after digestion compared to the control indicative of a heterozygous state and was confirmed by sequencing of the PCR product.

NAIP Gene: Amplification of Exon 5

(Forward Primer: 5'-AAGCCTCTGACGAGAGGATC-3';

Reverse Primer 5'-CTCTCAGCCTGCTCTTCAGAT-3') NAIP gene was carried out using the following PCR conditions; initial denaturation $94^{\circ} \mathrm{C}$ for $10 \mathrm{~min}$; followed by 30 cycles of $94^{\circ} \mathrm{C}$ for min , $60^{\circ} \mathrm{C}$ for $30 \mathrm{sec}$, $72^{\circ} \mathrm{C}$ for $30 \mathrm{sec}$; final extension at $72^{\circ} \mathrm{C}$ for min. Exon deletions were indicated by the absence of a $435 \mathrm{bp}$ band.

\section{Results}

The mean age of onset for the childhood onset SMA (I, II and III) was $1.76 \pm 1.93$ years $(0.08-7.00)$ at the time of evaluation. Thirteen of the affected children were born to consanguineous parents (uncle-niece (21.6\%), first cousin (13.5\%)). Of these nine patients (males-five; females-four) had affected sibling(s). The creatinine kinase level among SMA Type I ranged from 37-678 U/L (mean- 264), SMA Type II, 250 - 462 U/L (mean -384), SMA Type III, 64 - 356 U/L (mean 135), SMA Type IV 109 - 920 U/L (mean - 460). Although the levels were above normal limits in the majority, they were not remarkably elevated. Muscle sample for histopathological study was obtained from the biceps in 14 patients belonging to SMA Type II-IV. The findings were suggestive of neurogenic process with evidence of atrophy and hypertrophic fibers and group atrophy.

Among the 16 patients clinically diagnosed to have SMA Type I, seven (43\%) showed deletions in the SM N and/or NAIP genes [Figure 2]. The age of onset varied from third trimester to seven months. Positive muscle biopsy could be obtained in three of these individuals. In seven patients with clinical features of SMA Type II, four (57\%) patients showed deletion of the SMN and/ or NAIP genes [Figure 2]. The age of onset ranged from

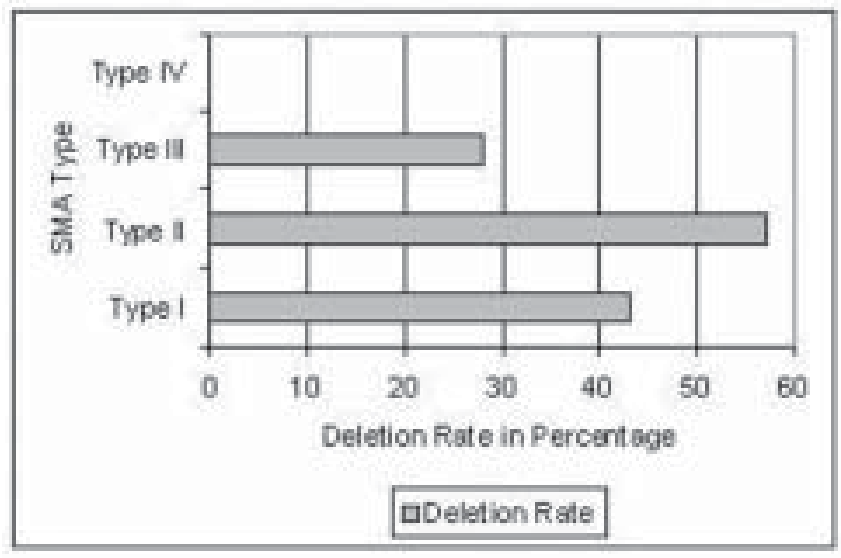

Figure 2: Representing the percentage deletion in the different SMA types one to two years. Three showed neurogenic process in muscle biopsy.

In seven patients clinically diagnosed to have SMA Type III patients, two (28\%) patients showed deletion of SMN and/or NAIP genes [Figure 2]. The age of onset ranged from three to seven years. Of the seven SMA Type IV patients, none showed deletions of the SMN exons [Figure 2].

\section{Discussion}

SMA was first recognized as a distinct entity about 115 years ago, with the nearly simultaneous clinicopathologic descriptions of Werdnig and Hoffman. ${ }^{[2-26]}$ SMA is one of the most frequent serious genetic disorders in children with an estimated birth prevalence of 1 in 10,000 births and a carrier frequency of 1 in 45 individuals. ${ }^{[27]}$ In our study, SMA Type I was uniformly defined by an onset before six months with severe weakness; however by genetic analysis only $43 \%$ showed the deletion. Among the SMA Type II cases a higher number of patients demonstrated the deletion.

Classification on the basis of clinical findings does not always permit unambiguous sub-grouping since the disease has phenotypic similarities with other childhood/floppy infant syndromes. ${ }^{[12]}$ Molecular diagnosis of childhood proximal SMA has been possible after the discovery of the SMN gene. ${ }^{[3 ; 18]}$ Deletions of Exons 7 and 8 of the SMN gene occur in 98.6\% and $93.0 \%$ of patients respectively, independent of the disease severity. ${ }^{[28]}$ NAIP is disrupted in $45 \%$ of patients with Type I disease and in 18\% of SMA II and III individuals and is thought to contribute to the severity of this disorder. ${ }^{[29]}$

The study by Labrum et al., reported a SMN 1 deletion rate of $51 \%$ among the South African SMA population. ${ }^{[30]}$ In a recent study by Dastur et al., from India, a deletion rate for SMN 1 of around $73 \%$ in Type I and 26\% in Type II SMA has been reported. ${ }^{[31]}$ Dua et al., in a study from North India reported deletions of the SM N 1 gene in $50 \%$ of cases. ${ }^{[32]}$ In another study by Kesari et al., from northern India, a homozygous deletion rate of $76 \%$ in SMA patients was demonstrated. ${ }^{[20]}$ In our study, the total rate of deletions in SMA Type I and II patients, accounted for around $47.8 \%$. Biopsies were done in 14 patients which showed neurogenic process. Among the 16 SMA Type I patients, eight showed neurogenic process on muscle biopsy and three of these demonstrated deletions in the SM N and/or N AIP genes. Of the four Type II patients with neurogenic process on muscle biopsy, three of them showed deletions of the SMN and/or NAIP genes.

In a study with adult onset SMA, the SMN gene was found to be deleted in all patients. These authors propose that there is genetic homogeneity between the clinically diverse adult onset form and childhood 
forms of the disease. ${ }^{[33]}$ However, in our study the seven patients with adult onset SMA showed no deletions of the SMN or NAIP genes.

An attempt was made to correlate the pathological and genetic findings. However, it did not demonstrate a direct correlation in all; this could be due to mutations or gene conversions that are being reported to cause SMA. These iatrogenic mutations and gene conversions could also be a possible explanation for the low rates of detected deletions in our study. It is also possible that particularly among the SMA Type I patients there could have been non-SMA floppy infant cases included as clinical assessment was utilized in the majority. The current diagnostic method of SMA is predominantly by the use of invasive techniques like muscle biopsy which is not a preferred method of diagnosis for infants. The advantage of using the PCR method for diagnostics is that it is convenient and noninvasive and could be preferred in infants and young children. Further, this method of genetic testing can be used in conjunction with other markers for prenatal diagnosis.

\section{Acknowledgment}

The authors acknowledge the Indian Council of Medical Research (ICMR), New Delhi for financial support extended to the 'Central Molecular Genetics Laboratory for Neurology and Psychiatry'.

\section{References}

1. Gilliam TC, Brzustowicz LM, Castilla LH, Lehner T, Penchaszadeh GK, Daniel RJ, \& al. Genetic homogeneity between acute and chronic forms of Spinal muscular atrophy. Nature 1990;345:823-5.

2. Zerres K, Rudnik-Schöneborn S. Natural history in proximal spinal muscular atrophy: Clinical analysis of 445 patients and suggestions for a modification of existing classifications. Arch Neurol 1995;52:518-23.

3. Panigrahi I, Kesari A, Phadke SR, Mittal B. Clinical and molecular diagnosis of spinal muscular atrophy. Neurol India 2002;50:117.

4. Biros I, Forrest S. Spinal muscular atrophy: Untangling the knot? J Med Genet 1999;36:1-8.

5. Stewart H, Wallace A, McGaughran J, Mountford R, Kingston H. Molecular diagnosis of spinal muscular atrophy. Arch Dis Child 1998; 78:531-5.

6. Lai AH, Tan ES, Law HY, Yoon CS, Ng IS. SMN1 Deletions among Singaporean patients with spinal muscular atrophy. Ann Acad Med Singapore 2005;34:73-7.

7. Munsat TL, Davies KE. International SMA consortium meeting (26-28 June 1992, Bonn, Germany). Neuromuscul Disord 1992;2:423-8.

8. Munsat TL. Workshop report- International SMA collaboration. Neuromuscul Disord 1991;1:81.

9. Thomas NH, Dubowitz V. The natural history of type I (severe) spinal muscular atrophy. Neuromuscul Disord 1994;4:497-502.

10. Engel M. Selective and non-selective susceptibility to muscle fibre types. Arch Neurol 1970;22:761-3.

11. Melki J, Sheth P, Abdelhak S, Burlet P, Bachelot MF, Lathrop MG, e al. Mapping of acute (type I) spinal muscular atrophy to chromosome 5q12-q14: The French Spinal Muscular Atrophy Investigators. Lancet 1990;336:271-3.

12. Melki J, Abdelhak S, Sheth P, Bachelot MF, Burlet P, Marcadet A, \&al. Gene for chronic proximal spinal muscular atrophies maps to chromosome 5q. Nature 1990;344:767-8.
13. Brzustowicz LM, Lehner T, Castilla LH, Penchaszadeh GK, Wilhelmsen KC, Daniels R, \& al. Genetic mapping of chronic childhood-onset spinal muscular atrophy to chromosome 5 q l 1.2-13.3. Nature 1990;344:540-1.

14. Lefebvre S, Burglen L, Reboullet S, Clermont O, Burlet P, Viollet L, et al. Identification and characterization of a spinal muscular atrophydetermining gene. Cell 1995;80:155-65.

15. Lefebvre S, Bürglen L, Frézal J, Munnich A, Melki J. The role of the SMN gene in proximal spinal muscular atrophy. Hum Mol Genet 1998; $7: 1531-6$.

16. Roy N, Mahadevan MS, McLean M, Shutler G, Yaraghi Z, Farahani R. The gene for neuronal apoptosis inhibitory protein is partially deleted in individuals with spinal muscular atrophy. Cell 1995;80:167-78.

17. Lewin B. Genes for SMA: Multum in Parvo. Cell 1995;80:1-5.

18. Lorson CL, Hahnen E, Androphy EJ, Wirth B. A single nucleotide in the SMN gene regulates splicing and is responsible for spinal muscular atrophy. Proc Natl Acad Sci 1999;96:6307-11.

19. Singh RN. Evolving concepts on human SMN pre-mRNA splicing. RNA Biol 2007;4:7-10.

20. Kesari A, Misra UK, Kalita J, Mishra VN, Pradhan S, Patil SJ, \& al. Study of survival of motor neuron and neuronal apoptosis inhibitory protein gene deletions in SMA patients. J Neurol 2005;252:667-71.

21. Mishra VN, Kalita J, Kesari A, Mitta B, Shankar SK, Misra UK. A clinical and genetic study of spinal muscular atrophy. Electromyogr Clin Neurophysiol 2004;44:307-12.

22. Miller S, Dykes D, Polesky H. A simple salting out procedure for extracting DNA from human nucleated cells. Nucleic Acids Res $1988 ; 16: 1215$

23. Wirth B, Herz M, Wetter A, Moskau S, Hahnen E, Rudnik-Scho“neborn $\mathrm{S}$, \& al. Quantitative analysis of survival motor neuron copies: Identification of subtle SMN1 mutations in patients with spinal muscular atrophy, genotype-phenotype correlation, and implications for genetic counseling. Am J Hum Genet 1999;64:1340-56.

24. Groger H, Guido Werdning. In: Ashwal S, editor. The founders of child neurology. Sanfrancisco, Calif: Norman Publishing; 1990. p. 383-6.

25. Hoffmann J. Ueber chronische spinale muskelatrophieim kindesalter auf familiarer basis. Dtsch Zeif Nervenheilk 1892. p. 427-70.

26. Hoffmann J. Ueberfamiliare progressive spinale muskelatrophie. Arch Psych (Berlin) 1892;24:644-6.

27. Cobben JM. DNA-studies in spinal muscular atrophy. Rijksuniversiteit Groningen, The Netherlands: 1996

28. Van der Steege G, Grootscholten PM, van der Vlies P, Draaijers TG, Osinga J, Cobben JM, \& al. PCR-based DNA test to confirm clinical diagnosis of autosomal recessive spinal muscular atrophy. Lancet 1995;345:985-6.

29. Akutsu T, Nishio H, Sumino K, Takeshima Y, Tsuneishi S, Wada H, \& al. Molecular Genetics of Spinal Muscular Atrophy: Contribution of the NAIP Gene to clinical severity. Kobe J Med Sci 2002;48:25-31.

30. Labrum R, Rodda J, Krause A. The molecular basis of spinal muscular atrophy in south african patients. Neuromuscul Disord 2007;17:68492 .

31. Dastur RS, Gaitonde PS, Khadilkar SV, Udani VP, Nadkarni JJ. Correlation between deletion patterns of SMN and NAIP genes and the clinical features of spinal muscular atrophy in Indian patients. Neurol India 2006;54:255-9

32. Dua T, Das M, Kabra M, Bhatia M, Sarkar C, Arora S, etal. Spectrum of floppy children in Indian scenario. Indian Pediatr 2001;38:1236-43.

33. Brahe C, Servidei S, Zappata S, Ricei E, Tonali P, Neri G. Genetic homogeneity between childhood-onset and adult-onset autosomal recessive spinal muscular atrophy. Lancet 1995;346:741-2.

Accepted on 05-09-2008

Source of Support: The Indian Council of Medical Research (ICMR), New Delhi provided financial support to the 'Central Molecular Genetics Laboratory for Neurology and Psychiatry', Conflict of Interest: None declared. 